\title{
Kleine-Levin Syndrome: Two Cases
}

\section{Kleine-Levin Sendromu: İki Olgu}

\begin{abstract}
Kleine-Levin syndrome is a rare disease characterized by periodic hypersomnia, cognitive impairment, and behavioral disorders, such as hyperphagia and hypersexuality. It is common among adolescents and males. It has an unknown etiology. Two patients were discussed with the backings of literature in order to increase the awareness of clinicians, considering that there is a limited information regarding the syndrome.
\end{abstract}

Keywords: Kleine-Levin syndrome, hypersomnia, polysomnography, multiple sleep latency test

\section{Öz}

Kleine-Levin sendromu, periyodik hipersomni, kognitif bozukluk, hiperfaji ve hiperseksüalite gibi davranış bozuklukları ile karakterize nadir görülen bir hastalıktır. Ergenlik döneminde ve erkeklerde sık görülür. Etiyolojisi bilinmemektedir. Az tanınan bir sendrom olması sebebiyle klinisyenlerin farkındalı̆̆ını artırmak amacıyla iki olgu literatür eşliğinde tartışılmıştır.

Anahtar Kelimeler: Kleine-Levin sendromu, hipersomni, polisomnografi, çoklu uyku latans testi

\section{Introduction}

Kleine-Levin syndrome (KLS) is a rare neuropsychiatric disease characterized by the triad of hypersomnia, changes in cognitive function, and behavioral changes (1). The age of onset of the disease is in the range of 4-82 years, with a mean age of 15 years. The symptoms of the disease usually appear in the twenties (2). The disease is four times more common in men (3) and its diagnosis is done clinically. The diagnostic criteria in the International Classification of Sleep Disorders-3 are: 1) At least two episodes of excessive sleepiness lasting between 2 days and 5 weeks; 2) the episodes are usually more frequent than once a year and they recur at least every 18 months; 3 ) between the episodes, the person is completely normal in terms of alertness, cognition, behavior, and effect; 4) hypersomnia is accompanied by at least one of the following: cognitive impairment, changes in perception, eating disorders (anorexia or hyperphagia), and disinhibited behaviors (hypersexuality) in the attack; 5) hypersomnia and related symptoms cannot be explained by another neurological or psychiatric disease (especially bipolar disorder). However, atypical/monosymptomatic patients that do not meet the criteria have also been reported in literature (4). Viral infections, head trauma, substance use (alcohol and marijuana), fever, stress, sleep deprivation, and menstruation are counted among the triggering factors. The etiopathogenesis of the disease is unknown, although alterations in serotonin and dopamine metabolism as well as hypothalamic dysfunction have been implicated. Moreover, autopsies revealed findings that are consistent with encephalitis in the hypothalamus and thalamus, thus suggesting a possible inflammatory cause in the etiology (5).

Two patients with KLS, which is rare, who were frequently confused with psychiatric diseases due to their findings and can be easily recognized with a careful anamnesis, are presented in this study, with the aim of increasing awareness of the disease.

Address for Correspondence/Yazışma Adresi: Gaye Yıldırım MD, Ordu State Hospital, Clinic of Neurophysiology, Ordu, Turkey Phone: +90 4522343232 E-mail: dr.gaye.eryasar@gmail.com ORCID: orcid.org/0000-0001-5699-5666 Received/Geliş Tarihi: 30.03.2021 Accepted/Kabul Tarihi: 20.05.2021

${ }^{\circ}$ Copyright 2021 by Turkish Neurological Society Turkish Journal of Neurology published by Galenos Publishing House. 


\section{Case Reports}

\section{Case 1}

A 20-year-old female patient was admitted to the sleep outpatient clinic with complaints of excessive sleepiness. The complaints emerged after a few days of upper respiratory tract infection and continued for one week. Her mother reported that she had more than 12 hours of sleep per day during this period, she woke up only for the needs of toilet and food, and that she responded late and slow to what was said to her. Her mother stated that she repeatedly asked the same questions. The patient did not remember this period exactly. These cognitive findings were accompanied by pessimism, crying fits, and tantrums from time to time. There was no change in her sexual behavior; however, her appetite decreased markedly.

The first attack of the patient appeared in the form of constant sleepiness and forgetfulness after flu at the age of 12 years and her attacks continued at a frequency of once a month until she reached the age of 13 years. This one-year period was almost forgotten. Some attacks were accompanied by agitation and aggressive behavior. She attempted suicide when she was 15 years old. It was learned that she was hospitalized in the psychiatry ward for 2 weeks due to the disease and was followed up by a child and adolescent psychiatrist for one year and received sertraline treatment. The duration of the attacks ranged from 1 week to 1 month. The frequency, duration, and severity of the 25 attacks she encountered up to the age of 20 had decreased over time. While it was once a month in the first year, there were a total of 15 attacks in the next 7 years. Her attacks were often triggered by stress and menstruation. The last attack she had, which lasted for three days, was 10 months ago and it consisted of excessive sleepiness, excessive eating, increased irritability, and increased desire to cry. There was no triggering cause. The patient's medical history and family history were unremarkable. There was no sexual behavior change in any of the attacks. She was completely normal in terms of appetite, sleep, and mood between attacks. Her neurological examination, cranial magnetic resonance imaging (MRI), and electroencephalography (EEG) were normal. Her complete blood count, biochemistry, thyroid function tests, B12 level, and hormone profile were also normal. On the fifth day of the attack, all-night polysomnography (PSG) was performed, while multiple sleep latency tests (MSLT) were performed in the next five days. Her total recording time in PSG, total sleep time, sleep latency, rapid eye movements (REM) sleep latency, and sleep efficiency was $465 \mathrm{~min}, 369 \mathrm{~min}, 8.5 \mathrm{~min}$, $185 \mathrm{~min}$, and $85.4 \%$, respectively. Her first period of non-REM sleep (N1) was $11.5 \min (2.9 \%)$, her second period (N2) was 301.5 $\min (76 \%)$, and her third period (N3) was 80.3 min $(20.2 \%)$. Her REM sleep period lasted $3.5 \mathrm{~min}(0.9 \%)$ and she remained awake for 68 min during sleep (Figure 1). No abnormal respiratory events (AHI: 0.6) that might cause excessive daytime sleepiness or periodic leg movements during sleep were detected. The mean sleep latency was $3.42 \mathrm{~min}$ in the MSLT performed five times the next day and no recording starting with REM sleep (SOREM) was detected. The patient, who was evaluated by psychiatry after the attack and in whom psychopathology was not considered, was followed up with the diagnosis of primary KLS.

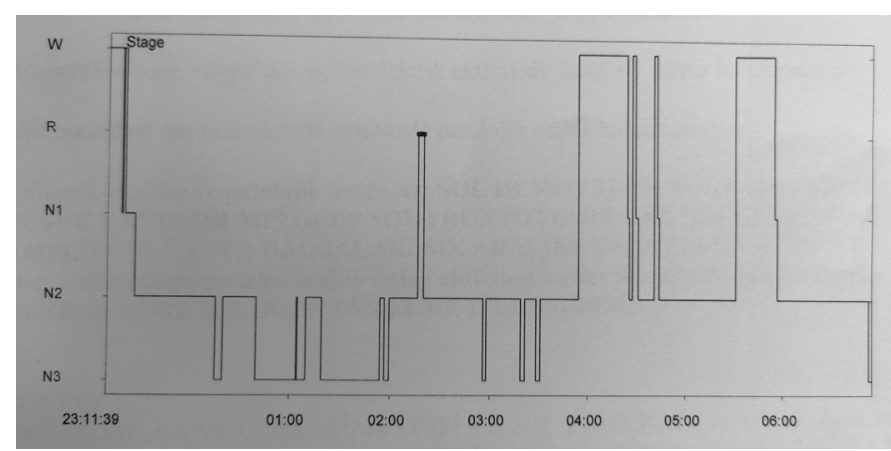

Figure 1. In the hypnogram, it is seen that sleep latency is short (8.5 minutes), sleep mostly follows NREM stage 2, REM sleep occurs for a very short time, and that wakefulness periods become more frequent in the second half of the night

REM: Rapid eye movements

\section{Case 2}

A 26-year-old male patient was admitted to the sleep outpatient clinic with the complaint of excessive sleepiness. In the examination, the patient was confused, answered the questions late, and had a depressive effect. He stated that he slept for 12-16 hours a day, did not want to wake up, felt unhappy, unwilling during the period of sleepiness, was too weak to get out of bed, and that he returned to his old self when this period was over. In the anamnesis taken from her mother, it was observed that he exhibited aggressive behavior when asked to wake up; he was sluggish and distracted while awake and answered questions with gestures rather than words. There was no change in his sexual desire and appetite during the attacks; however, his mother stated that he ate too much when he sat down to eat. He had his first attack when he was 17 years old. It was observed that the attacks recurred at the age of 21,23 , and 25 years and lasted about 10 days. Of the total of five attacks (which were the same) encountered by the patients, none of the attacks had a triggering cause. He was mentally and physically normal between the attacks. Neurological and psychiatric examination of the patient was normal. Cranial MRI and EEG examinations performed during the period other than the attacks were normal. On the fourth day of the attack, in the EEG examination performed with electrodes placed on the chin and ocular muscles, the ground rhythm was normal and no epileptiform abnormality was observed. Sleep latency was 12 min and REM sleep latency was $22 \mathrm{~min}$. Biochemical parameters, thyroid function tests, vitamin B12 level, and complete blood count were normal. At the end of the attack, which lasted 5 days, the patient's neurological examination was normal. The patient who was thought to have KLS was followed up in the sleep outpatient clinic.

\section{Discussion}

KLS is a rare disease with unknown etiopathogenesis. In a review of 186 patients, the symptoms reported were hypersomnia $(100 \%)$, cognitive changes (96\%), eating disorders $(80 \%)$, depressed mood (48\%), hypersexuality (43\%), and compulsions 
(29\%) (2). Hypersomnia, hypersexuality, and hyperphagia, which are classical findings, are not always seen together. In one study, the clinical triad was observed only in $45 \%$ of 108 patients (6) and many patients with KLS without behavioral symptoms were reported in literature (7). The main finding is hypersomnia and prodromal symptoms, such as a sudden feeling of extreme fatigue and difficulty in waking up in the morning, are common. Although patients can wake up spontaneously for food and toilet needs, they may exhibit aggressive behaviors when forced to wake up or when prevented from sleeping (2). In our two patients, hypersomnia was the most prominent finding, which was sometimes accompanied by agitation and aggression.

The eating disorders observed in KLS are generally in form of overeating (megaphagia). Although a very small percentage of patients $(5 \%)$ have anorexia during an attack, hyperphagia is frequently observed in other attacks (8). During an attack, they may exhibit unusual feeding habits (such as consumption of watermelon peel or a vegetarian patient eating animal food) and may show aggression when prevented. Compulsive eating and indulging in sweet foods can also be observed. Hypersexuality is rare among women but is seen in $50 \%$ of men (2). In our patients, hypersexuality was not accompanied. There was anorexia in our first patient and hyperphagia in the second patient.

Psychiatric symptoms often accompany KLS and depression is observed in approximately $50 \%$ of the patients. In a study including a total of 186 patients, $15 \%$ of the patients described suicidal thoughts during the attack, with 2 patients reportedly attempting suicide. In the same study, hypomania and anxious effect were defined in $8 \%$ and $7 \%$ of the patients, respectively (2). In our patients, the depressive mood was described during the attack. The first patient was hospitalized in the psychiatry clinic due to a suicidal attempt and received sertraline treatment for one year.

Cognitive disorders occur in almost all patients, with confusion, difficulty in concentrating, and attention and memory disorders being common. Mental retardation and amnesia during the attack are also common findings. Speech abnormalities are observed during the attack in two-thirds of the patients. Spontaneous loss of speech, speaking with a single syllable or word, incoherent speech, retardation of speech rate, and perseverations can be seen (2). Although mental retardation and amnesia were present in both patients, perseverations were remarkable in the first patient.

KLS is a clinical condition with no diagnostic test (2). Therefore, there are investigations regarding its differential diagnosis. MRI can be performed to exclude encephalitis, spaceoccupying formations, stroke, and third ventricle tumors that can cause hypersomnia. EEG can be performed to exclude encephalitis and encephalopathies. The cerebrospinal fluid examination may be performed when central nervous system infection is suspected.

Drug and substance use, psychiatric diseases (atypical depression and bipolar disorder), sleep-related respiratory disorders, narcolepsy, menstruation-related hypersomnia, complex partial seizures, Kluver Bucy syndrome (bilateral temporal lobe lesions), metabolic encephalopathies, Herpes virus encephalitis, Lyme disease, and intermittent porphyria should be considered in the differential diagnosis. Due to stagnation, behavioral changes, and increased desire for sleep, these patients are usually first admitted into a psychiatric hospital and often diagnosed as having depression. However, in KLS, symptoms appear suddenly at the beginning of the attack and end abruptly and psychotic symptoms (such as hallucinations and delusions) are short-lived if accompanied hypnagogic and hypnopompic hallucinations can also be seen in KLS; however, there are no cataplexy and REM sleep behavior disorders. If these disorders accompany them, then narcolepsy should be considered. Cognitive changes and disinhibition symptoms are not seen in menstruation-related hypersomnia and may recur many times in a year, depending on the menstrual cycle. In KLS, on the other hand, the number of attacks does not exceed 2-3 episodes per year (3).

Contrast-enhanced cranial MRI, which was performed to exclude encephalitis and encephalopathy in our patients, was evaluated as normal. Biochemical parameters, vitamin B12 level, and thyroid hormones were normal. In KLS, retardation of the background rhythm and paroxysmal $4-6 \mathrm{~Hz}$ theta activity can be observed in EEG during the episode (9). The EEG examinations of our patients were normal.

PSG should be performed to exclude obstructive sleep apnea syndrome. In KLS, PSG mostly has no determinative feature (4). In several studies, the mean PSG data was not different from that of the control $(3,6)$. In PSG examinations of patients with KLS, the mean sleep duration was $445 \pm 122 \mathrm{~min}$, with $6 \pm 4 \%$ of all sleep evaluated in stage I, $56 \pm 9 \%$ in stage II, $19 \pm 11 \%$ in stage III, and $19 \pm 6 \%$ in REM sleep (2). While it was shown that the duration of stage III sleep increased ( $28 \%$ of total sleep time), Huang et al. (5) reported that sleep efficiency and duration of stage III sleep decreased and that frequent awakening was observed in the case series of 17 patients. REM latency was generally found to be normal or shortened (9) and REM sleep was not recorded rarely (7). In our first patient, REM sleep was significantly shortened and its latency was prolonged. The presence of frequent awakenings and the duration of sleep periods supported the information in literature (2). Considering the studies examining the MSLT in KLS, a shortening of sleep latency was reported generally (2). There were also studies that either detected SOREM (5) or did not detect SOREM (9). In our first patient, sleep latency was short and SOREM was not observed. SOREM was observed in the second patient. In the case reported by Karadağ et al. (10) similar to our patient, frequent awakenings and prolonged REM latency were found in PSG, sleep latency was found to be shortened in the MLST, and SOREM was not observed.

There is no proven treatment for KLS. Supportive treatment and education of the patient's relatives are recommended. During the attack, the patient should rest and stay in a safe environment. The patient should be closely monitored for symptoms of anxiety and depression and should be treated promptly if they develop these symptoms. It has been reported that modafinil can improve symptoms in some patients if administered at the beginning of an attack. Although stimulants shorten the duration of the attack, they cannot prevent recurrence and may cause paradoxical agitation in some patients. Antipsychotics, such as risperidone, are effective for prolonged psychotic symptoms and benzodiazepines are effective in relieving anxiety symptoms. In one study, amantadine was shown to be effective in prophylaxis and it was reported that it could terminate the episode in $42 \%$ of patients when started on the first day of the attack. Although lithium is among the preventive agents, the evidence has low reliability. Mood stabilizers, such as valproic acid, carbamazepine, phenytoin, gabapentin, and lamotrigine, were also not shown to be of definite 
benefit. Tricyclic antidepressants, selective serotonin reuptake inhibitors, and serotonin-norepinephrine reuptake inhibitors were found to be ineffective in prophylaxis (11).

The fact that a 24-hour PSG examination was not completed in our first patient and that PSG could not be performed in the second patient during the attack (due to laboratory conditions) constitute a limitation for our study. Since it is a disease that is frequently confused with psychiatric diseases and starts in adolescence in terms of clinical findings, the recognition of KLS will prevent the negativities arising from its misdiagnosis and treatment.

\section{Ethics}

Informed Consent: Written informed consent was obtained from the patients.

Peer-review: Externally and internally peer-reviewed.

\section{Authorship Contributions}

Surgical and Medical Practices: G.Y., A.S.E., Concept: G.Y., Design: G.Y., Data Collection or Processing: G.Y., A.S.E., Analysis or Interpretation: G.Y., A.S.E., Literature Search: G.Y., A.S.E., Writing: G.Y.

Conflict of Interest: No conflict of interest was declared by the authors.

Financial Disclosure: The authors declared that this study received no financial support.

\section{References}

1. American Academy of Sleep Medicine. The International Classification of Sleep Disorders—Revised. Hauri P Ed. Chicago: IL 2005. p. 297.

2. Arnulf I, Zeitzer JM, File J, Farber N, Mignot E. Kleine-Levin syndrome: a systematic review of 186 cases in the literature. Brain 2005;128:2763-2776.

3. Miglis MG, Guilleminault C. Kleine-Levin syndrome: a review. Nat Sci Sleep 2014;6:19-26.

4. American Academy of Sleep Medicine. International Classification of Sleep Disorders - Third Edition (ICSD-3). (2014) Darien (IL): American Academy of Sleep Medicine.

5. Huang YS, Lin YH, Guilleminault C. Polysomnography in Kleine-Levin syndrome. Neurology 2008;70:795-801.

6. Arnulf I, Lin L, Gadoth N, et al. Kleine-Levin syndrome: a systematic study of 108 patients. Ann Neurol 2008;63:482-493.

7. Karadeniz D, Erdem E, Gürdal A, et al. Monosympatomatic Kleine-Levin syndrome: a case report. Cerrahpasa J Med 2000;31:243-248.

8. Portilla P, Durand E, Chalvon A, et al. Hypoperfusion temporomésiale gauche en TEMP dans un syndrome de Kleine-Levin [SPECT-identified hypoperfusion of the left temporomesial structures in a Kleine-Levin syndrome]. Rev Neurol (Paris) 2002;158:593-595.

9. Adlakha A, Chokroverty S. An adult onset patient with Kleine-Levin syndrome responding to valproate. Sleep Med 2009;10:391-393.

10. Karada $\breve{g ~ H, ~ A l ı s ̧ ı r ~ B, ~ O ̈ r s e l ~ S, ~ T u ̈ r k c ̧ a p a r ~ H . T h e ~ K l e i n e-L e v i n e ~ S y n d r o m e: ~ A ~}$ Case Report. Klinik Psikiyatri 2010;13:92-96.

11. Gadoth N, Kesler A, Vainstein G, Peled R, Lavie P. Clinical and polysomnographic characteristics of 34 patients with Kleine-Levin syndrome. J Sleep Res 2001;10:337-341. 